führungen bereits hingewiesen haben. Allerseits wird eifrig an der weiteren Vervollkommnung der einzelnen Methoden und an der weiteren Ausgestaltung dieses so wichtigen und aussichtsvollen Problems gearbeitet, und es ist wohl kaum daran zu zweifeln, daß uns die nächsten Jahre noch weitere Fortschritte bringen werden. Ist doch das, was bis heute erreicht wurde, sicherlich nur als das Anfangsstadium einer weiteren großen technischen Entwicklung zu betrachten.

\section{Über die Zersetzungstemperatur des amerikanischen Kolophoniums.}

\author{
Von Dr. C. Schwaliz. \\ (Eingeg. d. 26.110. 1905.) \\ (Vorläufige Mitteilung.)
}

Ts chirch und $\mathrm{Studer} \mathrm{r}^{1}$ ) haben in einer Untersuchung des amerikanischen Kolophoniums als Hauptbestandteil $83,6 \%$ ein Gemenge dreier isomerer Abietinsäuren erkannt. Außerdem wurden. gefunden : $5-6 \%$ Resen, das die Autoren als braune, zähe Masse beschreiben, $0,4-0,7 \%$ ätherisches $O 1$ and $0,1 \%$ Unreinigkeiten. Die Destillation des Harzes im Vakuum aus einem Eisenrohr ergab eine hellgelbe kolophonartige Masse, aus der sich Abietinsäure durch Kristallisation aus Ätheralkohol in kleiner Menge gewinnen ließ. Aus Glasgefäßen konnte das Kolophonium nicht destilliert werden.

Dagegen gelang es E a sterfield und B a $g\left(e y^{2}\right)$, Kolophonium aus Glasgefäßen bei einem Druck von $31 \mathrm{~mm}$ Quecksilber und einer Temperatur von $270-290^{\circ}$ zum gröBten Teil unzersetzt zu destillieren. Stieg der Druck auf über $100 \mathrm{~mm}$, so war eine weitergehende Zersetzung nicht zu vermeiden. Besondere Beschleunigung erfuhr diese, wenn anstatt aus einem Glaskolben aus einer Eisenretorte destilliert wurde. Der feste Anteil des Destillates erwies sich als ziemlich reine Abietinsäure; der flüssige Destillatanteil ließ sich als ein flüssiger Kohlenwasserstoff ,A b i e t e $\mathrm{n}^{\text {", }}$ $\mathrm{C}_{18} \mathrm{H}_{28}$, von $340-345^{\circ}$ bei $760 \mathrm{~mm}$ Druck siedend charakterisieren. Die Zersetzung besteht also in einer Kohlendioxydabspaltung aus der Abietinsäure, dem wesentlichen Bestandteil des Harzes. Erhitzt man nach Easterfield und Bagley Abietinsäure mit Jodwasserstoff, so entsteht ebenfalls Kohlendioxyd. Ein mögliches Vorhandensein von Hydroxylgruppen an Stelle einer Carboxylgruppe in der Abietinsäure, wie es $\mathrm{Tsch}$ i r ch

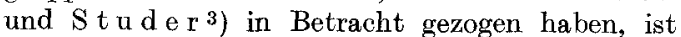
nach dem Befund von Easterfield und B a g l e y höchst unwahrscheinlich.

Im Hinblick auf die Bedeutung des amerikanischen Kolophoniums als Leimungsmittel für die Papierindustrie schien es mir von Wert, der inter-

1) Vgl. die Dissertation von $\mathrm{S} t \mathrm{u} d \mathrm{e} x$, Bern 1903; Archiv d. Pharm. 241, 495-522 (1903).

2) Journ. Soc. Chem. 85, 1239-1249 (1904).

3) S t u d e r, Dissertation, S. 103. essanten Beobachtung von Easterfield und B a g l e y nachzugehen und die Erhitzung des Kolophoniums unter Bedingungen zu studieren, wie sie sowohl bei der Fabrikation wie bei der Verwendung des Harzes rorkommen könnten. Bei der Herstellung des Kolophoniums wird das rohe Fichtenharz mit Wasserdampf destilliert, bis Terpentinöl nicht mehr übergeht. Die rückbleibende Harzmasse wird darauf durch Schmelzen vom anhängenden Wasser befreit. Wird diese Entwässerung über freiem Feuer vorgenommen, so ist eine Uberhitzung weit über den Schmelzpunkt des Harzes - die Angaben über die Sehmelztemperatur schwanken zwischen $50-70^{\circ}$ und $85-130^{\circ}$ kaum zu vermeiden. Aber auch bei dem Entwässern des Harzes durch indirekten Dampf können je nach der Spannung des Heizdampfes Temperaturen von $120-150^{\circ}$ in Betracht kommen. Das gleiche gilt von dem Schmelzen des Harzes behufs Bereitung von Harzleim.

Ich habe daher amerikanisches Kolophonium in einem Glaskolben in einem Strom kohlendioxydfreier Luft allmählich auf $160^{\circ}$ erhitzt. Bei einer Badtemperatur (Ölbad) von ca. $150^{\circ}$ und einer Innentemperatur von $135^{\circ}$ stiegen aus dem geschmolzenen. Harz Gasblasen auf. Ließ man den aus dem Kolben tretenden Luftstrom durch Barytwasser streichen, so trat kräftige Kohlendioxydreaktion, Fällung von Baryumcarborat, ein. Setzte man dem Kolbeninhalt vor der Erhitzung Eisenfeilspäne zu, so ließ sich die Gasentwicklung schon bei ca. $140^{\circ}$ Badtemperatur und $120^{\circ}$ Innentemperatur konstatieren. Amerikanisches Kolophonium bzw. Abietinsäure als wesentlicher Bestandteil spalten also schon bei einer Temperatur von $120-130^{\circ}$ unter Atmosphärendruck Kohlendioxyd ab, eine für die Zersetzung einer Carbonsäure auffällig niedrige Temperatur. Die Abspaltung von Kohlendioxyd muB vor allem den Schmelzpunkt des Harzes beeinflussen, da das Zersetzungsprodukt Abieten nach $\mathbf{E}$ asterfield und $B$ a gley flüssig ist, desgleichen muß die Verseifungszahl eine Änderung erfahren, wenn Kolophoniumharz auf die Zersetzungstemperatur erhitzt wird. An einem größeren Material verschiedener Harzsorten soll festgestellt werden, ob und in welchem Maße die Verschiedenheit der Harzsorten durch den verschiedenen Gehalt an Abieten in Folgen längeren oder kürzeren Erhitzens bei der Herstellung bedingt wird.

Darmstadt, den 14. Oktober 1905.

\section{Über Obst und Obstverwertung.}

\author{
Von Dr. H. RühLE-Stettin. \\ (Eingeg. d. 4.)10. 1905.)
}

Die Uberzeugung von der Wichtigkeit, welche eine sachgemäße Verwertung des Obstes sowohl im Hinblick auf den Nationalwohlstand wie nicht minder für die Gesundheit und Wohlfahrt des Einzelnen und der Gesamtheit besitzt, ist noch nicht so weit verbreitet, daß es überflüssig erscheinen könnte, an dieser Stelle einen Uberblick über den derzeitigen Stand der heimischen Obstverwertung zu geben, wobei Gelegenheit genommen werden soll, 